\title{
A TRADICIÓN BÍBLICA E CLÁSICA NA POESÍA DE CARVALHO CALERO (CON COMENTARIO DE CINCO POEMAS)
}

\author{
THE BIBLICAL AND CLASSICAL TRADITION IN THE POETRY OF CARVALHO CALERO \\ (WITH COMMENTARY ON FIVE POEMS)
}

\section{Xosé Manuel Vélez Latorre}

\begin{abstract}
Resumo: Neste estudo tratamos a importancia dos mitos grecorromanos (e tamén dos mitos bíblicos) na poesía de Carvalho Calero. $\mathrm{O}$ mito sérvelle non só como simple adorno estético ou culturalista, senón como medio de reflexión, nunha poesía filosófica e existencial de transfundo cristián. Algúns poemas de Salterio de Fingoy tratan a Orfeo, Dionisos, Xoán o Bautista e Salomé. Analízase o poema "Abisag", publicado xa en 1931; un dos primeiros exemplos da recepción da poesía de Rilke no ámbito ibérico. Analízase tamén o poema sobre Catulo "Onde eu escrevo Lésbia, lé ti Clódia", en que se dá unha reflexión metaliteraria sobre a voz lírica e a figura (e a realidade) da amada poética; un exemplo interesantísimo de recepción da tradición clásica nun poeta moderno. Os últimos poemas analizados son os dedicados á figura de Fénix e Aquiles, que parten dun profundo coñecemento por parte de Carvalho da Ilíada de Homero, en concreto da situación do Libro 9 deste poema épico. A situación de Aquiles nese episodio ten curiosas semellanzas coa situación biográfica de Carvalho con respecto aos seus antigos amigos e compañeiros do grupo Galaxia. En todo caso, Carvalho é un mestre do xogo hipertextual na súa poesía.
\end{abstract}

Abstract: This study analyses the importance of Greco-Roman myths (and also biblical myths) in Carvalho Calero's poetry. For Carvalho, myth is not merely an aesthetic ornament or a cultural display, but a means of reflection in order to achieve a philosophical and existentialist poetry with a strong Christian background. Some poems from Salterio de Fingoy [Fingoy's Psalter] feature the figures of Orpheus, Dionysus, John the Baptist and Salome. The poem 'Abisag', published in 1931 is analysed as one of the first examples of Rilke's poem of the same 
name in Iberian literatures. It also examines Carvalho's poem about Catullus, 'Onde eu escrevo Lésbia, lé ti Clódia' ['Where I write Lesbia, you should read Clodia'], with its metaliterary reflections on the lyrical voice and the figure (and reality) of the beloved: a very interesting example of the reception of classical tradition in modern poetry. The final poems analysed are the two works about the figures of Phoenix and Achilles, a subject which come from the Ninth Book of Homer's Iliad. Achilles' situation in that book has interesting similarities with Carvalho's situation with regards to his former intellectual colleagues in the Galaxia Group. The study concluded by assessing Carvalho's contribution as the most interesting and complex example of intertextual play with the classical tradition in modern Galician poetry.

Palabras chave: Ricardo Carvalho Calero, poesía, mitoloxía, tradición clásica, Catulo, Aquiles.

Key words: Ricardo Carvalho Calero, poetry, mythology, classical tradition, Catullus, Achilles.

\section{O USO DOS MITOS NA POESÍA DE CARVALHO: NIN DESMITIFICACIÓN, NIN DE-SACRALIZACIÓN}

1.1 .

O tratamento do mitos bíblicos e dos mitos grecorromanos na poesía de Carvalho prodúcese de diversos modos ${ }^{1}$. En ocasións serve para unha evocación do mundo clásico ou dunha pasaxe dunha obra literaria grega ou romana que tratan ese mito. Noutras ocasións, evócase unha imaxe, unha estatua ou un cadro. Ás veces é unha aproximación irónica, que xoga co contraste entre o Mundo Antigo e o Mundo Actual, e non poucas veces, cun humorismo peculiar. Outras veces, utiliza a reflexión sobre o mito clásico para introducir unha meditación seria sobre temas existenciais que preocupaban os seres humanos da súa época²

1 Sobre a temática cultural na poesía de Carvalho Calero, véxase o capítulo correspondente no libro de Rodríguez Fer (1989, pp. 35-77). Ben entendido que neste traballo non se trata dun estudo, en xeral, do "culturalismo" ou da abundacia de referencias culturais e literarias na poesía de don Ricardo, senón específicamente do seu tratamento da mitoloxía grecolatina (e bíblica) e da tradición clásica a partir da recepción da obra de dous autores, un romano (Catulo) e outro grego (Homero) en poemas concretos da súa obra.

2 Para o uso do mito grecorromano na literatura, e na arte en xeral, do século XX, véxanse Lasso de la Vega (1989) e José Manuel Losada (2016). A mellor aproximación ata o momento sobre o uso dos mitos grecolatinos, e doutras culturas, na poesía de Carvalho Calero é Pallarés (2002). 
Neste último sentido, en moitas ocasións converte Carvalho a personaxe do heroe mítico e as súas aventuras nun símbolo do ser humano contemporáneo, en procura da verdade ou da transcendencia. Ao facer isto, seguía Carvalho unha tradición que xa viña do Mundo Antigo, especialmente do mundo da filosofía (Platón): a interpretación moral dos mitos. Véxanse poemas de Futuro condicional como o poema 29 de "Excalibur" ou moitos da sección "Avalon" (así o poema "Tántalo", que en realidade reproduce e reinterpreta no xeito existencialista o mito de Sísifo).

Esa tendencia, no ámbito pagán, acentuouse na interpretación dos mitos clásicos por parte dos cristiáns. Estes, que rexeitaban a relixión politeísta grecorromana e a súa mitoloxía, aceptaron en ocasións unha lectura moral dos mitos e mesmo unha identificación de certos trazos dalgunha figura heroica mítica con figuras do mundo cultural e relixioso xudeu e cristiá que aparecen na Biblia. Ricardo Carvalho Calero recorre, efectivamente, en certas ocasións, a unha mestura de elementos pagáns grecorromanos cunha interpretación xudeocristiá; nisto fai algo parecido ao que facían os Santos Pais. Estes aproveitaban o material cultural pagán na medida en que podía ser posto ao servizo da doutrina cristiá, feito que se denominou co termo grego chresis, 'aproveitamento'.

Hai dous destacados exemplos na obra cumio da poesía de Carvalho, Salterio de Fingoy (1961); unha obra atravesada pola reflexión sobre a transcendencia, Deus e o sentido da existencia humana ${ }^{3}$. No seu poema "A bacante e Dionisos", a interpretación do tormento que sofre a bacante, da anulación do seu ser, é moi semellante á do papel que se dá ao sufrimento do crente na ascética e na mística cristiá (imitatio Christi): a crente debe sufrir e morrer para fundirse co deus/Deus, no Máis Alá.

Outro exemplo, moi explícito, é o poema "In memoriam", en que se fai unha síntese da figura cristiá do Xoán o Bautista coa figura pagá de Orfeo. Hai que lembrar que neste libro Carvalho trata o mito de Salomé e Xoán o Bautista en dous poemas. O primeiro, titulado "Salomé", é o poema 9 da sección "Novelo de pantasmas". No segundo, "In memoriam" (poema 7 da última sección do libro, 'Oratorio') Xoán o Bautista é comparado expresamente con Orfeo: igual que Orfeo movía as feras e animais salvaxes a seguilo coa súa música, Xoán o Bautista conmove mesmo os animais salvaxes coa súa mensaxe, que anuncia a inminente chegada do Salvador. Esta equiparación resulta curiosa e novidosa na tradición cristiá, dado que nesta (xa na antigüidade tardía) o que se tendía era a facer unha equiparación entre Orfeo e o propio Xesucristo.

3 O mellor estudo sobre a poética de Salterio de Fingoy ata o momento é o de Herrero Figueroa (1981). 
A mesma equiparación entre Orfeo e Xesucristo é precisamente a que aparece no seguinte poema da sección 'Oratorio', o número 8 , poema que pecha o libro: "A bacante e Dionisos". Aí a bacante, no seu sufrimento, é identificada de modo claro co místico cristián, que por medio do sufrimento e da depuración do elemento humano e terreal se acerca ao ámbito divino e á inmortalidade, e mesmo á figura de Cristo, home e Deus.

\section{2}

Un poema importante no tratamento da tradición bíblica é "Abisag", do libro Vieiros (1931). Este poema pertence á obra poética temperá de Ricardo Carvalho Calero. É un poema importante por dúas razóns: por un lado, é testemuño do interese de Carvalho pola lingua alemá e pola poesía de Rainer Maria Rilke ${ }^{4}$ quen xa escribira un poema sobre a figura de Abisag. Por outro lado, anticipa parte do tratamento posterior dos mitos bíblicos (e grecorromanos) no noso autor; esa recreación dos mitos grecolatinos na poesía moderna que se dará en Carvalho está tamén inspirada pola que fai Rilke nos seus Novos poemas, unha obra que o autor ferrolán sen dúbida coñecía moi ben. Carvalho, xunto con Xosé María Díaz Castro no seu libro Nimbos, son os dous autores de poesía galega que máis fortemente recibiron a influencia da lectura directa de Rilke.

Os claros precedentes rilkianos para o poema "Abisag" de Carvalho, aínda non estudado, inclúen tanto o poema "Abishag" (en dúas partes), como o poema "David canta ante Saúl" (tamén en dúas partes), ambos os dous parten dos Neue Gedichte de Rilke.

Pero, á parte disto, hai un verso clave no que fala de que, no medio do seu éxtase amoroso non-carnal con Abisag, "a arpa (de David) soou/cantou sen ninguén”. A alusión á arpa de David é una clara alusión metapoética: na antigüidade tardía e na Idade Media era un modo de xustificar a composición de poesía por parte dos cristiáns. Pero aquí a idea de Carvalho Calero é moi novidosa e audaz dentro da tradición. A arpa de David "toca soa" como consecuencia do amor non-carnal, puro e ideal, con Abisag. Aquí Carvalho alude a una visión elevadísima da creación poética impulsada por unha poesía amorosa, idealizada e pura, que remite ao Cantar dos cantares. Anulada a personalidade de David como a persoa que tanxe a arpa e canta, e polo tanto a inspiración de Iavéh ao seu Rei Unxido e Poeta, é o propio amor puro (en todo caso, impulsado por Abisag) o que tanxe a arpa.

4 Hai que recordar que o outro testemuño da recepción de Rilke en Galiza foi o grande amigo de Carvalho, Luís Tobío, tradutor dos Sonetos a Orfeo. Máis tarde chegaría a recepción de Rilke por parte de Xosé María Díaz Castro no seu libro Nimbos (1961) e noutros poemas. 
Por outra banda, neste poema Carvalho fai unha síntese/fusión dos temas que aparecían en catro dos Neue Gedichte -Erster Teil de Rilke: os dous sobre Abisag, e os dous sobre Saúl tocando a arpa para David.

\title{
1.3 .
}

Na cuarta sección do poemario Salterio de Fingoy (1961) é especialmente importante a presenza bíblica, a mitoloxía clásica (e especificamente o papel da muller na mitoloxía e a literatura universal), a reflexión sobre a teoloxía (teodicea, escatoloxía), o ben e o mal, a espiritualidade e a historia, e o papel da relixión nas identidades e no mundo contemporáneo. Son oito poemas que traen xa in nuce un aviso do tratamento do mitos grecolatinos e das figuras heroicas deses mitos que Carvalho desenvolverá na súa poesía posterior: tanto en Futuro Condicional (1961-1980), como nos seus dous libros finais dos anos 80, Cantigas de amigo e outros poemas e Reticências...

\section{O POEMA DE CARVALHO SOBRE LESBIA E CATULO: UN XOGO DE ESPELLOS}

\author{
Onde eu escrevo Lésbia lê ti Clódia. \\ 1 \\ Se te mascaro é para conhecer-te. \\ E o teu nome de outono pende inerte, \\ na árvore do teu ser folha serôdia. \\ Trado de luz, furo a tua escura côdia, \\ à procura do nó que te concerte, \\ clave de sol que trocará, solerte, \\ a oda mentida em certa palinódia. \\ O nome que eu escrevo te tatua \\ dumha flora de lume que a pel nua \\ despe da tua batismal paródia. \\ Mas se o alento do mundo embaça o espelho, \\ e che é mester o cotidiám vencelho, \\ onde eu escrevo Lésbia, lê ti Clódia.

Neste soneto de Carvalho, incluído en Cantigas de amigo e outros poemas, o autor ferrolán presenta a figura de Catulo e a da súa amada poética, á que o poeta latino chama nos seus poemas co nome de Lesbia ${ }^{5}$. Carvalho entra na polémica iniciada

5 Complementamos con este estudo do poema o breve comentario realizado polo profesor Lillo (1996, pp. 298-299). 
desde as Quaestiones Catullianae de L. Schwabe, sobre se se debe identificar a Lesbia cunha muller real da Roma da época de Catulo; coa Clodia Metelli que coñecemos polas fontes históricas. Hai que recordar que a partir desa identificación desenvolveuse toda unha 'novela' sobre as relacións entre Catulo e Clodia, que marcou durante moitos anos os estudos filolóxicos e literarios sobre a obra do autor. Só desde que se reivindicou a autonomía do texto fronte aos referentes históricos 'reais' (e mesmo fronte ao 'autor' ou as 'intencións do autor') na crítica literaria, púidose poñer en cuestión esa 'novela biográfica' de Catulo e Clodia/ Lesbia. Este cuestionamento produciuse no momento en que o "New criticism" norteamericano criticou a "falacia biográfica" na lectura de moitos autores literarios. Sobre o problema da identificación entre texto e realidade exterior ao texto, sobre a mediación do autor ou da instancia autoral e sobre o papel da recepción por parte do lector tamén reflexiona, en realidade, o presente poema do poeta (pero tamén crítico literario) Carvalho Calero. Toda a complexidade das cuestións literarias e metaliterarias que rodean este poema fai que este soneto do autor ferrolán sexa unha das máis logradas pezas da súa poesía, una poesía en que cada poema (e escribiu e publicou centos) é unha obra mestra.

Carvalho, profesor e crítico literario, coñecía ben a discusión que se producira sobre a relación entre autoría, 'eu' lírico ou voz lírica, texto, realidade exterior ao texto e recepción do texto por parte do lector nos anos 60 e 70. No contexto do "New criticism", Kenneth Quinn xa fixera esa crítica na súa obra The Catullan revolution, referida precisamente a estes temas na obra do poeta de Verona.

En todo caso, o 'eu' lírico enunciador do poema xa fora posto en cuestión polo propio Catulo, que no famoso poema "Mihi par esse videtur", se dirixe a si mesmo, 'desdobrando' en certo modo a súa propia personalidade, a súa propia voz.

Cando un poeta moderno quere render homenaxe a un poeta antigo ou reflexionar sobre a súa poesía ou poética, hai dous recursos básicos. Un deles é que o poeta moderno manteña a súa propia voz, manteña o seu 'eu' lírico de enunciador (o autor do texto), e interpele a figura do poeta antigo. Outra é que o poeta moderno fale coa voz do poeta antigo, tomando a máscara, a persoa, do poeta antigo: é o que fai aquí Carvalho. Hai que partir neste poema dunha 'impersonación' que fai Carvalho da figura do poeta Catulo: o 'eu' do poema é o propio Catulo.

A reflexión de Carvalho é sobre o feito de inventar un nome distinto para a amada, de modo que se crea unha personaxe literaria, Lesbia, diferente (?) do referente real, Clodia. Non obstante, esta reflexión pode estenderse á propia creación dunha obra poética, ás relacións entre poesía e verdade, na tradición pessoana ("O poeta é um fingidor...").

Utilizando o soneto, Carvalho aproveita o estrito marco fixo da métrica para acentuar a complexidade estrutural. $\mathrm{O}$ poeta utiliza seis referentes/conxuntos 
metafóricos para referirse ao proceso de creación da amada poética a partir da persoa real da amada.

O primeiro é o da máscara e está expresado a modo de oxímoro: "Se te enmascaro é para coñecerte". A máscara que pon o poeta, a creación da amada literaria, é o único modo que ten o poeta de coñecer a súa amada: creándoa.

O segundo referente metafórico é o da árbore; por detrás está o eco da figura do escultor que corta a árbore, saca a fronde, quita a codia, procura o celme e a partir do interior da madeira crea unha escultura. $\mathrm{O}$ primeiro paso deste proceso de liberar a árbore dos elementos exteriores é a caída da folla: "o teu nome de outono" evoca as follas da árbore que caen nesa estación. Pero aquí hai un referente ao que sabemos da Clodia histórica, ou polo menos, da Clodia da "novela de Clodia e Catulo". Clodia era entre nove e once anos maior ca Catulo; era xa unha muller madura, casada (e logo viúva), de aí que Catulo/Carvalho fale dun "nome de outono". O “nome de outono” é 'Clodia', que caerá como folla en outono. En realidade, os versos 3-6 desenvolven a primeira comparación da amada cunha árbore: o labor do poeta é despoxala desa folla morta, furar a súa codia, buscar o seu celme ("nó", verso 6).

O terceiro esquema metafórico é o da composición musical e o descubrimento da "clave" que permite modular esta. Habilmente, esta última metáfora enlaza precisamente co labor de Catulo como poeta introducindo dous termos técnicos propios da metalinguaxe dos estudos literarios relacionados coa poesía antiga. $\mathrm{O}$ primeiro é a “oda” (moitos poemas de Catulo son 'odas', é dicir, poemas en esquemas líricos da poesía eólica grega, en estrofas de catro versos, como a oda sáfica e a oda alcaica). O segundo é a "palinodia": ben coñecida é a de Estesícoro de Himera, a 'palinodia a Helena'. Esta referencia de Carvalho, aínda que ten ecos de Horacio (a Canidia do poeta de Venusia), tamén ten ecos de Catulo: no seu poema 42, o autor de Verona critica primeiro unha das súas amantes porque ela agora o insulta e non lle quere devolver unha copia dos seus poemas; pero nos dous últimos versos do poema, para conseguir que cambie a súa sorte, o poeta fai unha (mentida e irónica) palinodia gabando a beleza desa muller.

$\mathrm{O}$ cuarto esquema metafórico relaciónase coa pel e a tatuaxe. $\mathrm{O}$ poeta escribe sobre a pel da amada "unha flora de lume" que ao mesmo tempo ispe a súa pel.

O quinto referente metafórico é o bautismo, un referente cristiá que ten que ver coa asignación dun nome a alguén. O que fai o poeta (Carvalho/Catulo) é unha "bautismal parodia" porque é a parodia dun bautismo, é dicir, dar un novo nome a Clodia é unha 'parodia' (outro termo da retórica e da metalinguaxe da crítica literaria), unha imitación burlesca dun bautismo. Pero en realidade o novo nome vai ser o auténtico nome da amada (o que descubra a súa verdadeira identidade): ese 
nome 'ispe' a amada do outro nome que a 'bautismal parodia' lle deu e lle asigna desde a súa infancia (todo nomear é, pois, parodia!).

O sexto referente metafórico e simbólico é o do espello. $\bigcirc$ "alento do mundo" embaza o espello: é dicir, as circunstancias do mundo exterior, da persoa real da amada, impiden que ela vexa no espello ese novo 'eu' que creou o poeta, esa 'Lesbia'. Esa amada, que agora se arreda (como a Clodia na 'novela biográfica' do amor Catulo-Clodia) do poeta, volverá ser Clodia; necesita o vencello co cotián ("o cotidiám vencelho", v. 11) na medida en que se afasta da súa existencia na poesía do autor. Aí termina o poema, de forma circular, pero ese "Onde eu escrevo Lésbia lê ti Clódia” xa ten outro sentido: o da despedida, totalmente contrario ao do primeiro verso, en que se trataba da creación de Lesbia a partir da Clodia do mundo real, exterior.

Pero non só se alude, no final do poema, ao distanciamento final entre Catulo e a súa amada poética ${ }^{6}$. Tamén se alude a aqueles lectores modernos (estética da recepción) que precisan da identificación Lesbia-Clodia Metelli para dar sentido á poesía de Catulo.

Finalmente, neste xogo de espellos e personae ("máscaras") poéticas, hai que pensar na contribución neste poema da persoa do poeta Carvalho Calero como poeta amoroso, tan presente na súa obra, especialmente en Cantigas de amigo e outros poemas.

En todo caso, pois, temos neste soneto varios niveis de lectura: un poema amoroso, unha homenaxe a Catulo e unha reflexión metaliteraria que chega aos aspectos da composición do propio texto. A composición circular do poema recorda tamén o uso do quiasmo que fai Catulo (no poema "Odi et amo..."). Cando un poema se basea no esquema do quiasmo A B b' a', o elemento a' non é o mesmo que A; produciuse un enriquecemento do sentido ao longo do poema.

\section{CARVALHO CALERO, HELENISTA: AQUILES E FÉNIX EN DOUS POEMAS}

No seu penúltimo libro de poemas, Cantigas de amigo e outros poemas (1980-1985), na última sección do libro, a sección VIII, nas páxinas 177 e 179 aparecen, cos números 3 e 4 , dous poemas sen dúbida interrelacionados. Son dous poemas

6 Véxase o poema 11 de Catulo: "Furi et Aureli...", que representaría unha despedida final da súa amada. 
sobre as figuras mitolóxicas de Fénix e Aquiles ${ }^{7}$, baseadas no Libro 9 da Ilíada de Homero ${ }^{8}$.

A figura do personaxe homérico de Fénix, o preceptor e conselleiro de Aquiles (xunto co centauro Quirón, pero Fénix acompaña a Aquiles a Troia) aparece en dous poemas que poderían verse como un só: "Isto é o que nos foi dado. Mais nada", e "Administrar o capital do nosso destino".

Resulta curioso que Carvalho Calero, que demostra aquí un profundo coñecemento da Ilíada, acuda a un episodio dos que parecen menos importantes do poema de Homero, pero moi revelador do carácter do heroe Aquiles. Fai unha seria reflexión por medio dun xogo literario, dado que os dous poemas están cheos de ironía, porque aquí Carvalho Calero inverte precisamente os papeis que Aquiles e Fénix teñen no subtexto orixinal.

En realidade, trátase nos dous poemas de palabras que Aquiles podería dirixir a Fénix; poderían considerarse un só poema, dado que a voz enunciadora non parece cambiar, é a voz de Aquiles; aínda que, ao non ser presentado explicitamente como tal, pódese fundir coa do enunciador lírico.

Fénix, na Ilíada (IX, vv. 427-619), forma parte da embaixada de heroes aqueos, xunto con Áiax e Odiseo/Ulises, que acoden con agasallos á tenda de Aquiles para tentar unha reconciliación con Agamenón polo asunto de Briseida. Fénix recoméndalle a Aquiles prudencia no conflito con Agamenón e que acepte as ofrendas que lle son feitas.

Na Ilíada, Fénix cóntalle a Aquiles a historia de Meleagro e a súa rabia contra o seu propio pobo, paralela á que Aquiles sente contra os seus compañeiros no bando aqueo, en especial contra Agamenón.

A ironía deste discurso de Fénix a Aquiles é que, no poema de Carvalho Calero, é Aquiles quen lle "recomenda" a Fénix prudencia. Se na Ilíada o que fai un brillante discurso retórico é Fénix, aquí o papel retórico corresponde á voz enunciadora do poema, que podemos supoñer que é a de Aquiles.

Curiosamente, a "resposta" irónica que Carvalho pon en boca de Aquiles presenta a Fénix dous "contra-exemplos" que Fénix o prudente non debe seguir: Ícaro e Faetón. Curiosamente, os dous van morrer en plena xuventude tentando unha fazaña sobrehumana: voar. Aquiles vai tamén morrer en plena xuventude na busca da gloria, do kléos, na guerra de Troia.

Na Ilíada, Fénix, ademais, dille a Aquiles que debe aceptar as ofrendas que traen os heraldos e negociar con Agamenón por dúas razóns: a primeira, porque

7 Lillo Redonet (1997, pp. 278-80) fai unha análise doutra presenza homérica na poesía de Carvalho, o poema sobre "Nausícaa", de Futuro condicional.

8 Ambos os dous poemas foron recollidos na antoloxía Fillos de Eva, preparada por Pilar Pallarés, que dá algunhas notas sobre os personaxes citados nestes poemas (1992, pp. 187 n. e 188 n.). 
a aceptación de agasallos e a negociación con heraldos son propias da sociedade civilizada; e a segunda, polas obrigas relixiosas que supoñen a situación en que se encontra: as Súplicas, personificadas, divinizadas, son fillas de Zeus.

Fénix proponlle a Aquiles dous exemplos claros do comportamento que debe ter: un positivo (a súa propia xuventude, en que non se deixou levar pola furia e non matou a seu pai) e un negativo (a historia de Meleagro que levou a súa furia contra a súa xinea e pobo). Curiosamente, o logos do Aquiles de Carvalho Calero fai, primeiro, unha proposición "en negativo" (o que Fénix non debe facer) e despois unha en positivo (o que Fénix e Aquiles deben facer).

No segundo poema de Carvalho Calero, Aquiles non fai ningunha alusión aos deuses, senón que fai un contraste entre as dúas actitudes vitais de Fénix e de Aquiles. Fénix é un "supervivente nato" segundo o mito grego. "Administrar o capital do nosso destino,/ é umha forma de viver": Fénix consegue, a pesar de todas as súas desgrazas, seguir vivindo, sobrevivir.

O Aquiles de Carvalho ten un curioso ton gnómico, utilizando comparacións para referirse ao modo de asumir o destino do ser humano (xogo de cartas, carreira de cuadrigas, no primeiro poema; a metáfora bancaria do capital e as moedas no segundo poema). Aquí preséntase unha teoría fatalista e heroica da inmobilidade do ethos ou carácter de cada personaxe; o supervivente será supervivente, o heroe debe comportarse como heroe asumindo a súa morte.

Este Aquiles de Carvalho, de modo moi semellante ao de Homero, escolle unha especie de "fatalismo heroico"; prefire arriscarse a morrer gloriosamente e en plena xuventude: "Querer trocar a moeda do nosso destino / é umha forma de morrer". Aquiles prefire unha gloriosa morte. E faino por pura coherencia, asumindo a súa mortalidade, vendo no cumprimento do seu ethos heroico o sentido da súa existencia. O Aquiles da Ilíada, como o Aquiles de Carvalho neste poema, aparece como o primeiro heroe existencialista.

Esa é a razón de que, na Ilíada, se negue a negociar con Agamenón. En realidade, a coherencia entre o Aquiles de Carvalho Calero e o do propio Homero da Ilíada é total; o que introduce Carvalho é o xogo literario de presentar a Aquiles falando como un mestre da retórica e da ironía.

Porque estes dous poemas son tamén unha gran peza retórica de Carvalho Calero. Os discursos do Libro 9 da Ilíada eran vistos na antiga Grecia como a orixe da retórica. Cada un dos tres heroes que intentan convencer a Aquiles de que negocie con Agamenón utiliza unha das tres posibilidades da retórica: Odiseo/Ulises utiliza o logos, o razoamento hábil; Fénix o pathos, presentándose como unha especie de "segundo pai" de Aquiles, Áiax o ethos, aludindo a que se Aquiles deixa de combater por causa dunha moza fai traizón á súa condición e comportamento de heroe guerreiro. Carvalho escolle presentar no seu poema (que en realidade 
é un poema sobre Aquiles) a Fénix, pero tendo en conta sempre os outros dous heroes, que están na mente do lector ou lectora que coñece o subtexto homérico.

Se analizamos a situación orixinal do episodio da Ilíada en que se basean os dous poemas de Carvalho, a posición de Aquiles, a do heroe que está disposto a morrer en plena xuventude por acadar a gloria, tamén pode estenderse a outro personaxe presente na escena homérica, Patroclo, e quizáis a Áiax. E a postura vital de Fénix, a do hábil supervivente, aseméllase á de Odiseo/Ulises, tamén presente na escena en Homero e sen dúbida, de modo tácito pero intertextualmente necesario, no poema de Carvalho. De feito, o intercambio de discursos entre Odiseo/Ulises e Aquiles, anterior ao intercambio de Fénix e Aquiles, xira tamén arredor das obrigas que supón o ethos heroico.

A última ironía do poema vén nos versos finais: na peculiar visión do mundo deste Aquiles/Carvalho as dúas actitudes vitais representan as dúas caras da mesma moeda. As actitudes dos dous personaxes son irreconciliables, pero quizais necesarias para que exista ese contraste. No Alén, a vida de Fénix e a morte de Aquiles "convergirám, como paralelas no infinito". Mais se son paralelas, nunca converxerán.

Por outro lado, ese Alén, dinnos Aquiles e Carvalho Calero, é chamado "autenticidade": para Aquiles e para Carvalho, pois, a única autenticidade está na arte, na literatura, dado que tanto Aquiles como Fénix son personaxes literarios.

Estes dous poemas teñen unha posición importante na derradeira sección do libro Cantigas de amigo e outros poemas (queremos postular que estes son os "outros poemas"): a sección VIII, que trata o tema da extrema vellez, da fin da existencia e do sentido último da vida.

E, neste sentido, estes dous poemas son unha reivindicación do propio Carvalho Calero nun curioso sentido. Aquiles, ao separarse da colectividade bélica dos aqueos e negarse a combater, pola ira que esperta nel o comportamento de Agamenón, fai unha reivindicación da súa autosuficiencia como heroe e como individuo fronte á comunidade, fronte ao colectivo. Tamén Carvalho Calero, nos anos 80 , uns anos difíciles en que rompeu o contacto con moitos dos que foran os seus antigos compañeiros na loita cultural do grupo da Editorial Galaxia, reivindica esa autosuficiencia. Do mesmo xeito que a rebelión de Aquiles contra Agamenón e o resto dos líderes aqueos, a rebelión de Carvalho Calero ten, pois, deixando á parte o seu aspecto filosófico e existencial, unha clara intención política.

\section{CONCLUSIÓN FINAL}

Como se ve por estes exemplos presentados, cando Carvalho recorre a un hipotexto grego ou latino para o seu xogo intertextual ou hipertextual (Genette 1982), o poeta de Ferrol presenta a lectura como un xogo literario que esixe, para a súa 
plena comprensión, unha investigación por parte do lector, un coñecemento moi detallado do poema grego ou romano obxecto de recepción, pero tamén doutros textos antigos, do seu contexto e das súas implicacións. Carvalho dá case sempre alusións indirectas das súas fontes mitográficas ou literarias clásicas e esixe un gran traballo de interpretación por parte do lector. Neste sentido, é un poeta plenamente "alexandrino" ". Só cun pleno coñecemento dese xogo hipertextual pode o lector chegar a unha completa atribución de sentido ao poema; ou mellor dito, a abrir todo o amplo abano de posibilidades de sentido.

\section{REFERENCIAS BIBLIOGRÁFICAS}

Baldomir Cabanas, Xohán X. (2007). A poesía de Ricardo Carvalho Calero en Futuro Condicional (1961-1980). Boletín Galego de Literatura, 36-37, 7-36. Dispoñible en http://hdl.handle.net/10347/2126

Carvalho Calero, Ricardo (1992). Fillo de Eva. (88 poemas de Ricardo Carvalho Calero). Ferrol: Sociedade de Cultura Valle Inclán. Edición de P. Pallarés.

Genette, Gérard (1982). Palimpsestos. La literatura en segundo grado. Madrid: Taurus.

Herrero Figueroa, Araceli (1981). A procura da transcendencia en Salterio de Fingoy. Grial, 74, 480-489.

Lasso de la Vega, José (1989). La presencia del mito griego en nuestro tiempo. Gerión, 2 (núm. extra), 99-114.

Lillo Redonet, Fernando (1996). Algúns usos da mitoloxía clásica na poesía galega de Pondal, Cunqueiro e Carballo Calero. Galicia dende Salamanca, 1, 67-87.

Lillo Redonet, Fernando (1997). La temática homérica en la poesía gallega. Cuadernos de Filología Clásica. Estudios griegos e indoeuropeos, 7, 263-286.

Lillo Redonet, Fernando (1998). Presencia de Catulo y Tibulo en la poesía gallega del siglo XX. Cuadernos de Filología Clásica. Estudios Latinos, 14, 285-299.

Losada, José M. (2016). Los mundos del mito. En: José M. Losada, ed. Mitos de hoy. Ensayos de mitocrítica cultural. Berlin: Logos-Verlag, 109-185.

Pallarés, Pilar (2002). Carvalho Calero. Mitos para un exílio. En: Teresa López e Francisco Salinas, eds. Actas do Simposio Ricardo Carvalho Calero. "Memoria do século". A Coruña: Universidade da Coruña / Asociación Socio-Pedagóxica Galega, 183-202.

Rodríguez Fer, Claudio (1989). Poesía galega. Crítica e metodoloxía. Vigo: Edicións Xerais de Galicia.

9 Sobre un modo de recepción da Tradición Clásica e un xogo intertextual "alexandrino" parecido noutros dous poeta galegos, Eduardo Pondal e Aquilino Iglesia Alvariño, véxanse Vélez Latorre (2015, 2019). 
Vélez Latorre, Xosé M. (2015). A tradición clásica en Lanza de soledá (1961) de Aquilino Iglesia Alvariño: dun existencialismo agnóstico a unha relixiosidade mistérica. A Trabe de Ouro, 104, 61-73.

Vélez Latorre, Xosé M., (2019). Redescubrir Pondal para o século XXI: tradición clásica e creación poética n'Os Eoas. A Trabe de Ouro, 112, 69-82. 